Research Article

\title{
Formulation and Evaluation of Nanosuspension Drug Delivery System of Furosemide Produced
} by Nanoprecipitation Method

\author{
Suvarna S. Vadje ${ }^{1}$, Rajendra K. Surawase ${ }^{2}$, Santosh S. Surana ${ }^{3}$ \\ Department of Pharmaceutics; Loknete Dr. J. D. Pawar College of Pharmacy Manur, Kalwan, Maharashtra, 423501, India. \\ *Corresponding author's E-mail: Suvarnavadje259@gmail.com
}

Received: 18-09-2020; Revised: 21-11-2020; Accepted: 29-11-2020; Published on: 15-12-2020.

\begin{abstract}
Formulation of poorly water-soluble drug has always been a challenging problem confronted by the formulation scientist since more than the $40 \%$ of the new chemical entities being generated through the drug discovery programme are poorly water soluble. A poorly water-soluble drug indicates insufficient bioavailability. The purpose of this study was to formulate and evaluate the furosemide nanosuspension by nanoprecipitation method with the different stabilizer like Poloxamer 188, PVP K30 and tween 80 . The mixture of the drug and methanol as an organic phase and distilled water containing carrier as an aqueous phase. Nanosuspension containing Poloxamer $188(30 \mathrm{mg})$ and tween $80(10 \mathrm{mg})$ were selected to be the best based on their drug content, entrapment efficiency and particle size. The result showed that the prepared nanosuspension have particle size in the range of 0.0035 to $0.017 \mu \mathrm{m}$. The nanosuspension of furosemide was successfully prepared using nanoprecipitation method.
\end{abstract}

Keywords: Furosemide, Nanosuspension, Nanoprecipitation, Poloxamer 188.

QUICK RESPONSE CODE $\rightarrow$

DOI:

10.47583/ijpsrr.2020.v65i02.009

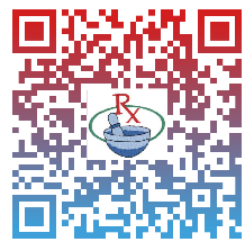

DOI link: http://dx.doi.org/10.47583/ijpsrr.2020.v65i02.009

\section{INTRODUCTION}

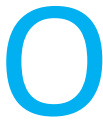

ral route of drug delivery is the most commonly used route because of its convenience, painless administration and patient compliance than other routes of drug administration. ${ }^{1}$ More than $40 \%$ of the NCEs generated through the drug discovery programme are poorly water soluble. Therefore the pharmaceutical industries seeking new approach in order to obtain an adequate oral bioavailability of this type of new chemical entities. Formulation of poorly water soluble or practically insoluble (i.e. BCS class II and BCS class IV drug) drug has always been a challenging problem confronted by the pharmaceutical scientist. ${ }^{2}$ There are various approaches have been used to solve the problems of poor solubility and bioavailability such as prodrug, salt formation, complexation (inclusion complexation with $\beta$ Cyclodextrin), Co-solvency, use of surfactant, liposomes, microemulsion etc., but these methods have the limitations such as requirement of the large amount of the additives induce the stability and toxicity issues. ${ }^{3}$ These methods lack the universal applicability to all drug. ${ }^{3,4}$ Nanotechnology can be used to solve the problems associated with the earlier approaches to enhance solubility and bioavailability. 5,6 Reduction of the particle size to nanoscale can be applicable to both BCS class II and IV to increase the solubility, dissolution and hence their absorption into the gastrointestinal tract. $^{7}$ Nanotechnology have various advantages over other conventional technology such as it can enhanced solubility, dissolvability, extends the oral bioavailability, lessens the amount of dose. There are various type of drug delivery system using the nanotechnology such as nanosuspension, solid lipid nanocrystals, nanoemulsion, etc. ${ }^{8,9}$ Nanosuspension preparation is technically easy, simple and less costly than other nanosizing method. ${ }^{10}$

Nanosuspension is the colloidal dispersion of the drug particle in an aqueous vehicle mainly water which is stabilized by the surfactant, polymer or mixture of the both, for either oral, topical use or the parenteral and the pulmonary administration, with the reduced particle size which leads to increase the dissolution rate and improved bioavailability. ${ }^{11,12}$ The particle size distribution of the solid drug particle in nanosuspension is usually less than 1 micron with an average particle size range in between 200 $600 \mathrm{~nm}^{13}$

Nanosuspension technology is most suitable for the compound with high log $\mathrm{P}$ value, high melting point and high dose. ${ }^{14-16}$ There are mainly two types of stabilizer used for the stabilization of nanosuspension - steric and electrostatic stabilizer. ${ }^{16}$ No single one stabilizer suitable for all drug nanosuspension. ${ }^{17}$ In the nanosuspension drug particle size reduction leads to an increase into the particle surface area and consequently the rate of dissolution as described by the Nernst-Brunner and Levich modification of the Noyes- Whitney equation. Increase in saturation solubility postulated by the particle size reduction due to increase into the dissolution pressure explained by Ostwald - Freundlich equation. ${ }^{11,} 18$ The Nanosuspension can be prepared by bottom- up technology, top- down and third one is the combination technology. The 'Bottom up

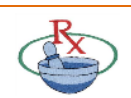


Technology' includes the method of precipitation. The 'Top Down Technologies' are the disintegration method. The top down technologies which include media milling (Nanocrystals), High Pressure homogenization in Water (Dissocubes), High Pressure Homogenization in Nonaqueous Media (Nanopure), and the combination of precipitation and High-Pressure Homogenization (Nanoedge). ${ }^{15,19}$

The aim of this present study was to develop furosemide nanosuspension using a precipitation method. The prepared nanosuspension was then characterized for the drug content, Entrapment efficiency, particle size and the final batch for saturation solubility study.

\section{MATERIALS AND METHODS}

\section{Materials}

Furosemide was obtained as a gift sample from Aquatic remedies, Mumbai. Polyvinylpyrrolidone $\mathrm{K} 30$ and Poloxamer 188 were procured from Balaji drugs, whereas Methanol was purchased from Fischer Scientific, Mumbai. All the ingredients used in the research work were of analytical grade.

\section{Method}

\section{Preformulation characterization}

In the preformulation characterization the physicochemical parameter of the drug substance are characterized with the goal of designing a drug delivery system.

\section{Organoleptic properties}

The pure drug substance was studied for the organoleptic properties such as color, odor, taste and appearance.

\section{Determination of melting point}

The melting point of the drug was determined by a capillary glass method. The melting point of the drug was determined by taking small amount of drug in a capillary tube that was closed at one end. The capillary tube was placed in thermionic melting point apparatus and the temperature at which the drug melt was noted. Observed values of the melting point compared with the reported values. $^{20,21}$

\section{Determination of $\lambda_{\max }$ by UV - Spectrophotometer}

The wavelength at which the drug absorbs to its maximum is called as $\lambda$ max. Drug has a characteristics $\lambda_{\max }$, and that cannot be changed easily. The $\lambda_{\max }$ of the substance can be find out by scanning the substance in the range of 200$400 \mathrm{~nm}$.

\section{Construction of Calibration curve in Methanol}

A stock solution of a pure drug furosemide of concentration $1000 \mu \mathrm{g} / \mathrm{ml}$ was prepared by dissolving accurately weighed a $10 \mathrm{mg}$ of furosemide in $10 \mathrm{ml}$ of Methanol. From this solution take $1 \mathrm{ml}$ and diluted upto $10 \mathrm{ml}$ with corresponding solvent $(100 \mu \mathrm{g} / \mathrm{ml})$. Appropriate volumes of the above solution $(0.2,0.4,0.8$, and $1 \mathrm{ml})$ were further diluted to obtained final concentration in range of 2 to $10 \mu \mathrm{g} / \mathrm{ml}$. The spectrum of this solution was recorded using UV; Visible Spectrophotometer against the blank (Methanol) in the range of 200-400nm.

\section{Solubility determination of Furosemide}

Solubility of the furosemide was determined qualitatively. $10 \mathrm{mg}$ of drug in $10 \mathrm{ml}$ of solvent (aqueous / Non-aqueous) taken in a conical flask. Different solvent were used for the solubility determination to determine the solubility of drug. After shaking the sample was examined for the presence of any undissolved suspended particles and clarity. ${ }^{22}$

\section{Preparation of Furosemide Nanosuspension}

Furosemide nanosuspension was prepared according to nanoprecipitation method. Pure drug furosemide was dissolved in a $(2 \mathrm{ml})$ methanol to form uniform organic solution. The stabilizer was dissolved in water $(50 \mathrm{ml})$ to form aqueous phase. The organic solution was injected slowly drop wise with the help of syringe into an aqueous phase with the mechanical agitation at $1000 \mathrm{rpm}$ for 30 minutes. After the mechanical agitation the formulation homogenized at $1500 \mathrm{rpm}$ for 120 minutes with the help of lab homogenizer.

Table 1: Formulation of Furosemide nanosuspension

\begin{tabular}{|c|c|c|c|c|c|c|c|}
\hline \multirow{2}{*}{$\begin{array}{l}\text { Formulation } \\
\text { Code }\end{array}$} & \multirow{2}{*}{ Drug } & \multicolumn{3}{|c|}{ Type of Stabilizer } & \multirow{2}{*}{$\begin{array}{l}\text { Methanol } \\
\text { (ml) }\end{array}$} & \multirow{2}{*}{$\begin{array}{c}\text { Water } \\
\text { (ml) }\end{array}$} & \multirow{2}{*}{$\begin{array}{l}\text { Stirring Speed } \\
\text { (R.P.M.) }\end{array}$} \\
\hline & & Poloxamer 188 & PVP K30 & Tween 80 & & & \\
\hline FNS1 & 20 & 5 & - & 5 & 2 & 50 & 1500 \\
\hline FNS2 & 20 & 10 & - & 10 & 2 & 50 & 1500 \\
\hline FNS3 & 20 & 15 & - & 10 & 2 & 50 & 1500 \\
\hline FNS4 & 20 & 20 & - & 10 & 2 & 50 & 1500 \\
\hline FNS5 & 20 & 25 & - & 10 & 2 & 50 & 1500 \\
\hline FNS6 & 20 & 30 & - & 10 & 2 & 50 & 1500 \\
\hline FNS7 & 20 & - & 5 & 5 & 2 & 50 & 1500 \\
\hline FNS8 & 20 & - & 10 & 10 & 2 & 50 & 1500 \\
\hline FNS9 & 20 & - & 15 & 10 & 2 & 50 & 1500 \\
\hline FNS10 & 20 & - & 20 & 10 & 2 & 50 & 1500 \\
\hline FNS11 & 20 & - & 25 & 10 & 2 & 50 & 1500 \\
\hline FNS12 & 20 & - & 30 & 10 & 2 & 50 & 1500 \\
\hline
\end{tabular}




\section{Characterization of Nanosuspension}

Particle Size analysis: The particle size of the formulated nanosuspension batches was determined by using the Motic digital microscope. The particle size of the batches was recorded in micrometer.

Entrapment Efficiency: Determination of entrapment efficiency is suitable for determining the free concentration of drug present in the supernatant after centrifugation. For the determination of entrapment efficiency $10 \mathrm{ml}$ of the freshly prepared nanosuspension was taken and centrifuged at $1000 \mathrm{rpm}$ for 10 minute. The supernatant was removed and the amount of drug unincorporated was measured by taking the absorbance of supernatant solution at $275 \mathrm{~nm}$ by using UV-Visible spectrophometer. ${ }^{9}$

Total drug content: An accurately measured nanosuspension equivalent to $10 \mathrm{mg}$ of drug was taken in $100 \mathrm{ml}$ volumetric flask and diluted to $100 \mathrm{ml}$ with methanol. (To prepare the stock solution of $100 \mu \mathrm{g} / \mathrm{ml}$ ). The amount of drug determined spectrophotometrically at $275 \mathrm{~nm}$. (UV Spectrophotometer LABINDIA $\left.3000^{+}\right) .{ }^{23,24}$

Saturation Solubility: Furosemide loaded nanosuspension $(5 \mathrm{ml})$ was subjected to centrifugation at $10000 \mathrm{rpm}$ for 30 minutes. After that the supernatant was examined for drug content by using UV- Visible spectrophotometer at $275 \mathrm{~nm} .^{25}$

\section{RESULTS AND DISCUSSION}

Furosemide is a BCS class IV drug which exhibits a low solubility and low permeability characteristics. The current investigation aimed to increase the solubility of furosemide by preparation of its nanosuspension by using nanoprecipitation technique using Poloxamer 188, PVP K30 and the Tween 80 as a stabilizer. According to the result the batch FNS21 shows better particle size than other. Therefore, this batch can be further evaluated for the saturation solubility. The results of saturation solubility indicate the improvement in saturation solubility than pure drug.

\section{Preformulation Characterization}

Table 2: Preformulation studies of Furosemide

\begin{tabular}{|c|c|c|c|}
\hline $\begin{array}{l}\text { Sr. } \\
\text { No. }\end{array}$ & Parameter & Observed value & $\begin{array}{l}\text { Reported } \\
\text { value }\end{array}$ \\
\hline 1 & $\begin{array}{l}\text { Organoleptic } \\
\text { properties }\end{array}$ & White & White \\
\hline I. & Color & Odorless & Odorless \\
\hline II. & Odor & Tasteless & Tasteless \\
\hline III. & Taste & Smooth & Crystalline \\
\hline IV. & Melting point & $204-208^{\circ} \mathrm{C}$ & $206^{\circ} \mathrm{C}$ \\
\hline 2 & $\begin{array}{l}\text { Determination of } \lambda_{\max } \\
\text { by UV- } \\
\text { Spectrophotometer }\end{array}$ & $275 \mathrm{~nm}$ in methanol & $275 \mathrm{~nm}$ \\
\hline 3 & $\begin{array}{l}\text { Preparation of } \\
\text { calibration curve of } \\
\text { Furosemide }\end{array}$ & $\begin{array}{l}\text { Linear standard } \\
\text { curve of Furosemide }\end{array}$ & - \\
\hline 4 & Solubility Studies & $\begin{array}{l}\text { Soluble in methanol, } \\
\text { acetone; insoluble in } \\
\text { Water }\end{array}$ & - \\
\hline
\end{tabular}

\section{Determination of Melting point:}

The melting point of the drug was found to be in the range of $204-208^{\circ} \mathrm{C}$. it complies with standards thus indicating the purity of the drug sample.

\section{Determination of $\boldsymbol{\lambda}_{\max }$ by UV - Spectrophotometer:}

From the number of dilutions of stock solution, the middle dilution i.e. 8 can be used for the determination of the maximum absorbance using UV-visible spectrophotometer in the range of $200-400 \mathrm{~nm}$. The absorption maximum and same was used as a $\lambda$ max for the estimation of furosemide. The $\lambda_{\text {max }}$ of the substance was found to be a $275 \mathrm{~nm}$.

\section{Construction of Calibration curve in Methanol:}

Furosemide in methanol showed absorption maxima at $275 \mathrm{~nm}$ and it was chosen as an analytical wavelength. The plot of concentration vs. the absorbance was plotted. Beer's law was obeyed in range 2 to $10 \mu \mathrm{g} / \mathrm{ml}$. Regression analysis was performed on the experimental data. Regression equation for experimental curve was $y=0.094 x+0.500$. The correlation coefficient was found to be 0.999 , which indicates the linear relationship between the concentration of drug and its absorbance. The calibration plot of drug in methanol was depicted in figure 1.

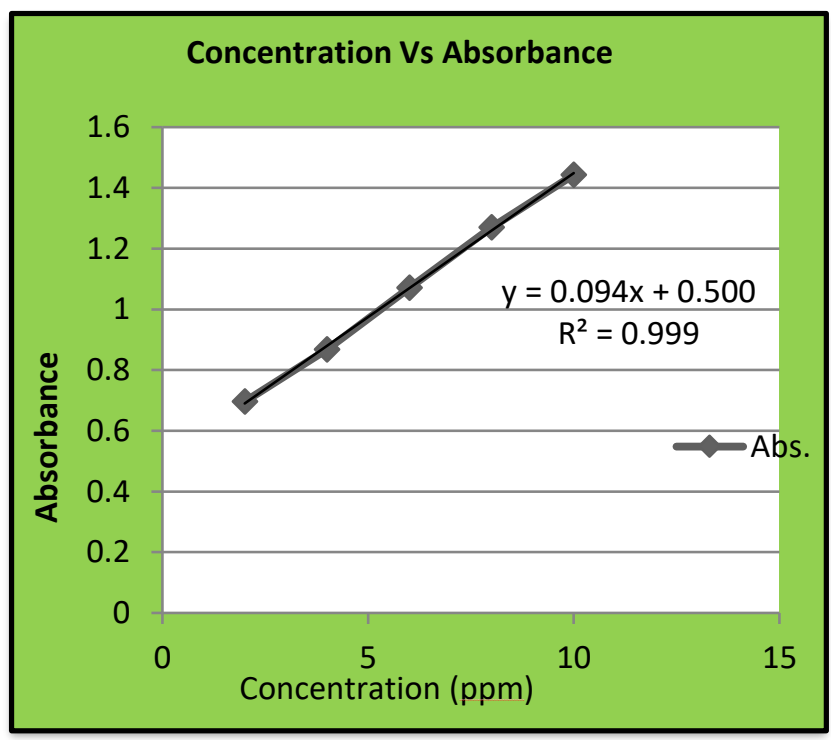

Figure 1: Calibration plot of furosemide in methanol.

\section{Solubility determination of furosemide:}

Solubility of the furosemide determined qualitatively. Furosemide is insoluble in water. Soluble in acetone and methanol.

\section{Particle size analysis:}

The particle size of the formulated nanosuspension batches was carried out by using Motic digital microscope. The particle size of the nanosuspension batches (FNS1 to FNS12) were shown in table. The average particle size of the FNS1 -FNS12 are in between the 0.0035 to $0.017 \mu \mathrm{m}$. According to result the batch FNS6 showed better particle size reduction than others. (Figure 2) 

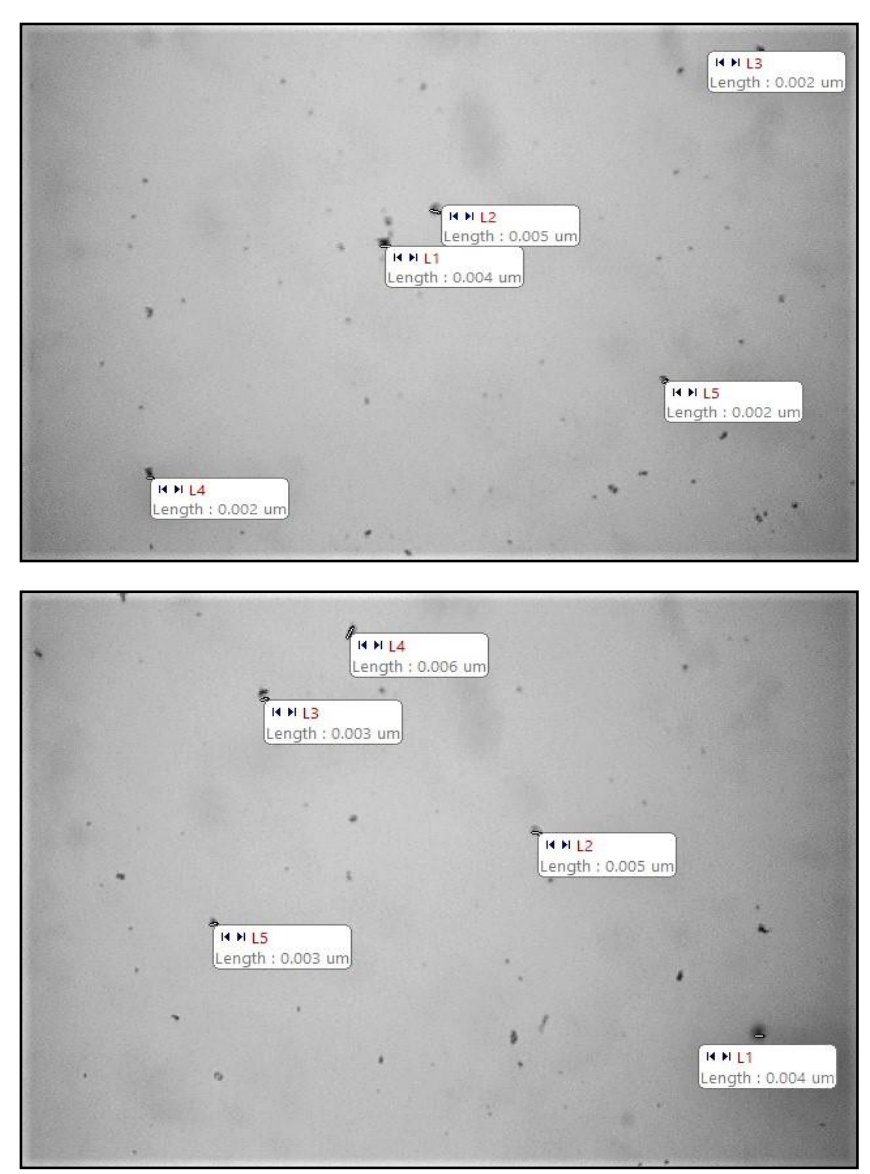

Figure 2: particle size analysis by Motic microscope of FNS21 and FNS20 batch.

Table 3: Particle size of the nanosuspension batches.

\begin{tabular}{|c|c|c|c|}
\hline $\begin{array}{c}\text { Formulation } \\
\text { Batch }\end{array}$ & \multicolumn{3}{|c|}{ Particle size $(\mu \mathrm{m})$} \\
\hline FNS1 & Max & Min & Average \\
\hline FNS2 & 0.011 & 0.004 & 0.0075 \\
\hline FNS3 & 0.012 & 0.002 & 0.006 \\
\hline FNS4 & 0.007 & 0.005 & 0.017 \\
\hline FNS5 & 0.006 & 0.003 & 0.005 \\
\hline FNS6 & 0.005 & 0.002 & 0.0045 \\
\hline FNS7 & 0.009 & 0.002 & 0.0035 \\
\hline FNS8 & 0.007 & 0.003 & 0.005 \\
\hline FNS9 & 0.012 & 0.009 & 0.0105 \\
\hline FNS10 & 0.012 & 0.003 & 0.0075 \\
\hline FNS11 & 0.013 & 0.004 & 0.0085 \\
\hline FNS12 & 0.013 & 0.001 & 0.007 \\
\hline
\end{tabular}

Entrapment efficiency: The entrapment efficiency of the nanosuspension batches is highlighted in figure 3 . It is observed that the formulation batch FNS7 shows minimum entrapment efficiency of $77 \%$ and formulation batch FNS6 shows maximum entrapment efficiency of $97.75 \%$. The entrapment efficiency of the nanosuspension was found to be in the range of $77 \%-97.75 \%$ respectively.

Total Drug Content: The drug content of the nanosuspension was in the range of 76.59 to $99.46 \%$ respectively, which indicates that loss of drug was lower during preparation process. The $\%$ drug content was shown in table 4. The total drug content of the entire nanosuspension batch was found to be greater than $75 \%$. The batch FNS6 shows the maximum total drug content of $99.46 \%$ and batch FNS7 shows minimum drug content, this can be shown in figure 4 .

Table 4: Drug content and Entrapment efficiency of the formulation batches.

\begin{tabular}{|c|c|c|}
\hline $\begin{array}{c}\text { Formulation } \\
\text { Code }\end{array}$ & $\begin{array}{c}\text { \% Drug } \\
\text { Content }\end{array}$ & $\begin{array}{c}\text { \% Entrapment } \\
\text { Efficiency }\end{array}$ \\
\hline FNS1 & 86.38 & 82.75 \\
\hline FNS2 & 96.80 & 84.25 \\
\hline FNS3 & 97 & 87.77 \\
\hline FNS4 & 97.87 & 97.5 \\
\hline FNS5 & 98.13 & 97.35 \\
\hline FNS6 & 99.46 & 97.75 \\
\hline FNS7 & 76.59 & 77 \\
\hline FNS8 & 78.1 & 78.75 \\
\hline FNS9 & 78.72 & 79 \\
\hline FNS10 & 81.06 & 81.38 \\
\hline FNS11 & 81.31 & 84.25 \\
\hline FNS12 & 84.04 & 87.78 \\
\hline
\end{tabular}

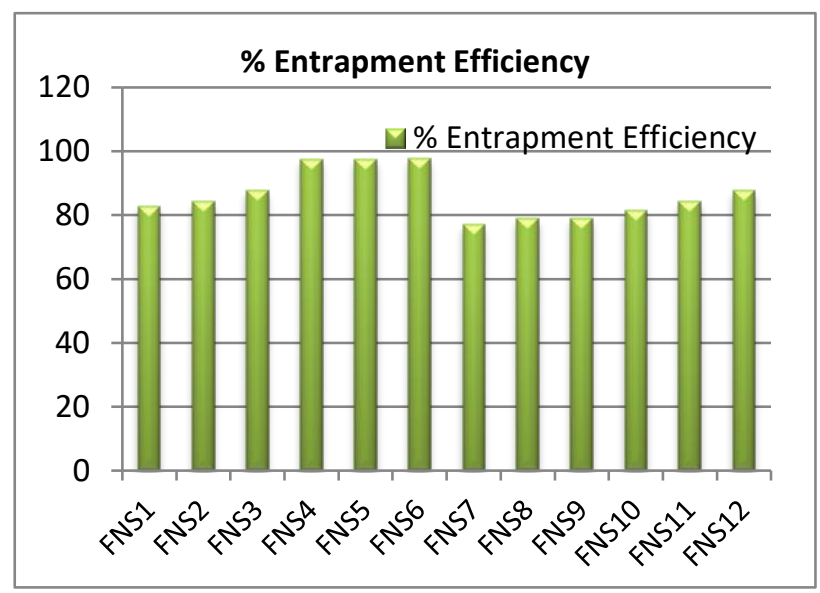

Figure 3: Entrapment efficiency of the formulated nanosuspension.

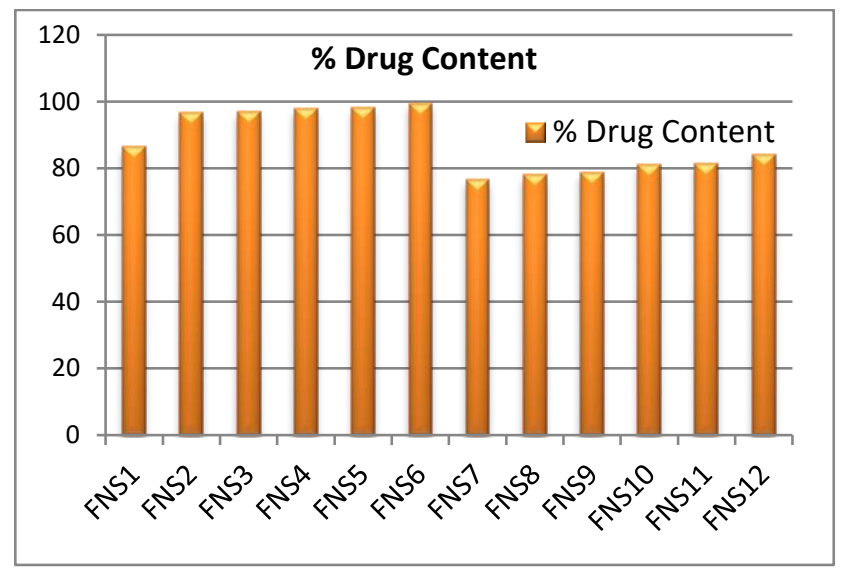

Figure 4: Drug content of the formulated nanosuspension 
Saturation solubility: The saturation solubility of the batch (FNS6) was $12.73 / \mathrm{ml}$ which was higher than that of the bulk drug.

\section{CONCLUSION}

Nanosuspension is the submicron colloidal dispersion of the drug particle. This drug delivery system is important in recent years. It offers the potential advantages like improve bioavailability and patient compliance over the other drug delivery system. In the present study the nanosuspension of furosemide was prepared by using Poloxamer 188, PVP K30 and tween 80 as stabilizers. Furosemide nanosuspension was successfully prepared by using nanoprecipitation technique. The evaluations result confirmed that prepared formulation exhibit satisfactory result. In this process the particle size of the furosemide can be obtained in nano-size ranges by adjusting the concentration of the stabilizer, organic phase volume, and the stirring speed. The best nanosuspension of the furosemide can be obtained by using $20 \mathrm{mg}$ of furosemide, $30 \mathrm{mg}$ of Poloxamer and $10 \mathrm{mg}$ of tween 80 as a stabilizer using nanoprecipitation at laboratory scale. This batch is evaluated for the saturation solubility indicates the improvement in the solubility of furosemide nanosuspension as compared to pure drug.

\section{REFERENCES}

1. Mayank Sharma Sharma M, Sharma R, Jain DK. Nanotechnology based approaches for enhancing oral bioavailability of poorly water soluble antihypertensive drugs. Scientifica., 2016.

2. Patravale VB, Date AA, Kulkarni RM. Nanosuspensions: a promising drug delivery strategy. Journal of pharmacy and pharmacology, 56, 2004, 827-40.

3. Jassim ZE, Rajab NA. Review on preparation, characterization, and pharmaceutical application of nanosuspension as an approach of solubility and dissolution enhancement. Journal of Pharmacy Research, 12, 2018, 771.

4. Shete G, Jain H, Punj D, Prajapat H, Akotiya P, Bansal AK. Stabilizers used in nano-crystal based drug delivery systems. Journal of Excipients and Food Chemicals, 5, 2016, 941.

5. Chandra A, Sharma U, Jain SK, Soni RK. Nanosuspension: an overview. Journal of Drug Delivery and Therapeutics, 3, 2013, 162-7.

6. Patel VR, Agrawal YK. Nanosuspension: An approach to enhance solubility of drugs. Journal of advanced pharmaceutical technology \& research, 2, 2011, 81.

7. Lakshmi P, Kumar GA. Nanosuspension technology: A review. Int J Pharm Sci., 2, 2018, 35-40.

8. Patel HM, Patel UB, Shah C, Akbari B. Formulation and Development of Nanosuspension as an Alternative Approach for Solubility and Dissolution Enhancement of Aceclofenac. International Journal of Advances in Pharmaceutics, 2018, 33-47.

9. Patil AM, Patil IN, Mane RU, Randive DS, Bhutkar MA, Bhinge SD. Formulation optimization and evaluation of cefdinir nanosuspension using factorial design. Marmara Pharm J., 22, 2018, 587-98.

10. Hitanga J, Sharma N, Chopra H, Kumar S. Nanoprecipitation technique employed for the development of nanosuspension: a review. World Journal of Pharmaceutical Sciences, 4, 2015, 2127-36.

11. Patel HM, Patel BB, Shah CN. Nanosuspension: a novel approach to enhance solubility of poorly water soluble drugs-a review. Int J Adv Pharm., 5, 2016, 21-9.

12. Yadav GV, Singh SR. Nanosuspension: A promising drug delivery system. Pharmacophore, 2012.

13. Geetha G, Poojitha U, Khan UA. Various techniques for preparation of nanosuspension-A Review. International Journal of Pharma Research \& Review, 3, 2014, 30-7.

14. Nayak BS, Mohanty B, Roy H, Patnaik A. Nanosuspension: Bioavailability Enhancing Novel Approach.

15. Shid RL, Dhole SN, Kulkarni N, Shid SL. Nanosuspension: a review. Technology, 2013, 30, 34.

16. Sundar V, Divya P, Sridevi P, Akhila K, Dhanaraju M. Design, Formulation and Evaluation of Nanosuspension for Drug Delivery of Celecoxib. International Journal of Pharmaceutical Research, 11, 2019.

17. Chen A, Shi Y, Yan Z, Hao H, Zhang Y, Zhong J, Hou H. Dosage form developments of nanosuspension drug delivery system for oral administration route. Current pharmaceutical design, 21, 2015, 4355-65.

18. Velmula M, Pavuluri P, Rajashekar S, Rao VU. Nanosuspension technology for poorly soluble drugs-a review. World Journal of Pharmacy and Pharmaceutical Sciences, 4, 2015, 1612-25.

19. Sutradhar KB, Khatun S, Luna IP. Increasing possibilities of nanosuspension. Journal of nanotechnology, 2013, 2013.

20. Ethiraj T, Sujitha R, Ganesan V. Formulation and In-vitro Evaluation of Nanosuspension of Glimepiride. Int. J Pharmacy, 3, 2013, 875-2.

21. Maddukuri S, Srawanthi P, Metta S, Radha GV, Krishna KS M. Screeening of Stabilizers in Azithromycin nanosuspensions. Int. J. Pharm. Sci. Rev. Res., 55, 2019, 77-84.

22. Anjane $M$, Agrawal $S$, Khan A. Formulation and evaluation of nanosuspension of Valsartan. Int. J Curr Pharm Res, 10, 2018, 68-74.

23. Nawale RB, Deokate UA, Shahi SR, Lokhande PM. Formulation and Characterization of Efavirenz 
nanosuspension by QbD approach. Research Journal of Pharmacy and Technology, 10, 2017, 2960-72.

24. Patel HM, Patel UB, Shah C, Akbari B. Formulation and Development of Nanosuspension as an Alternative Approach for Solubility and Dissolution Enhancement of Aceclofenac. International Journal of Advances in Pharmaceutics, 2018, 33-47.
25. Motka U, Dabhi M, Sheth N, Dudhrejiya A. Formulation and optimization of Nanosuspension Prepared by Media Milling Technique to enhance the solubility of Isradipine. International Journal of Pharmaceutical Sciences and Drug Research, 9, 2017, 169-77.

Source of Support: None declared.

Conflict of Interest: None declared.

For any question relates to this article, please reach us at: editor@globalresearchonline.net New manuscripts for publication can be submitted at: submit@globalresearchonline.net and submit_ijpsrr@rediffmail.com 